\title{
Implementasi Media E-Commerce Pada Pemasaran Kain Sutra Mandar Di Polewali Mandar
}

\author{
Asmawati S*1, Dian Megah Sari ${ }^{2}$ \\ ${ }^{1,2}$ Universitas Sulawesi Barat; Jl. Prof. Dr. Baharuddin Lopa, SH, telp/fax: 0422) 22559 \\ ${ }^{3}$ Program Studi Teknik Informatika, FTEKNIK UNSULBAR, Majene \\ e-mail: *11asmawati.s@unsulbar.ac.id, ${ }^{2}$ dianmegahsari@unsulbar.ac.id
}

\begin{abstract}
Abstrak
Saat ini penenun kain sutra mandar di Polewali Mandar masih memproduksi secara tradional dan para pedagangkain sutra mandar mengalami kesulitan dalam memasarkan produk tersebut, karena pemasaran yang dilakukan sampai saat ini masih terbatas pada event atau pameran budaya yang diikuti oleh para pedagangyang dominan masih bersifat individual dengan jumlah produk yang terbatas, sehingga hanya kalangan masyarakat tertentu yang memperoleh informasi mengenai kain sutra tersebut. Kendala dalam memasarkan kain sutra mandar sehingga diperlukan suatu media yang dapat digunakan untuk memasarkan produk tersebut yang dapat menjangkau semua area tanpa dibatasi ruang dan waktu.Berdasarkan indikator kualitas aplikasi, penggunaan aplikasi, kepuasan pengguna dan dampak bagi pedagang,respon pengguna pada uji coba lapangan dengan jumlah sembilan belas orang terdiri dari tujuh belas orang konsumen sebagai client dan pihak produsenataupedagang sebagai server atau admin, menunjukkan rerata 3,38 dengan presentase 84,60\% dengan kategori sangat baik, dapat disimpulkan bahwa pemanfaatan aplikasi e-commerce sangat membantu dalam pemasaran kain sutra mandar
\end{abstract}

Kata kunci-e-commerce, kain sutra mandar, pemasaran

\begin{abstract}
Currently mandar silk weavers in Polewali Mandar still produce traditionally and mandar silk merchants have difficulty marketing these products, because the marketing carried out to date is still limited to cultural events or exhibitions attended by dominant traders who are still individual. with a limited number of products, so that only certain groups of people get information about these silk fabrics. Constraints in marketing mandar silk cloth so that we need a medium that can be used to market these products that can reach all areas without being limited by space and time. Based on the indicators of application quality, application use, user satisfaction and impact on merchants, user responses in field trials with a total of nineteen people consisting of seventeen consumers as clients and producers or traders as servers or admins, showed a mean of 3.38 with percentage of $84.60 \%$ with very good category, it can be concluded that the use of e-commerce applications is very helpful in marketing mandar silk fabrics.
\end{abstract}

Keywords—e-commerce, mandar silk fabric, marketing

\section{PENDAHULUAN}

Pemanfaatan teknologi informasi di era globalisasi, khususnya penggunaan internet saat ini memberikan kemudahan hampir dalam segala bidang, baik itu pendidikan, pemerintahan, dan transaksi bisnis. Media online yang digunakan dalam transaksi jual beli untuk memperluas 
pemasaran dalam kegiatan penjualan saat ini adalah e-commerce. Penggunaan e-commerce dapat memudahkan Penjual dalam memberikan informasi terkait dengan harga atau melakukan pengaturan mengenai produk atau jasa yang ditawarkan secara cepat melalui website [1].

Penelitian yang dilakukan oleh Mifta menjelaskan bahwa penggunaan internet untuk transaksi bisnis sudah dianggap sebagai suatu hal yang penting, hal ini ditandai dengan meningkatnya jumlah pengusaha yang menggunakan e-commerce dalam perusahaannya [2]. Kemudahan menggunakan e-commerce memungkinkan konsumen untuk menjual produknya (barang atau jasa) langsung kepada pelanggan lain yang pada umumnya dipertemukan melalui situs bisnis tertentu. Hal tersebut didukung oleh penelitian dari [3] yang menjelaskan bahwa sistem e-commerce dapat memaksimalkan berbagai bentuk penjualan, pemasaran, dan kualitas pelayanan. Sistem e-commerce juga dapat menjadi media informasi yang memudahkan masyarakat, sebagai calon konsumen, untuk memperoleh informasis erta melakukan pembelian di mana pun dan kapan pun, serta sistem e-commerce mempunyai pengaruh dominan terhadap kepuasan konsumen bukalapak [4]

Kelebihan menggunakan e-commerce menurut Ahmadi Candra yaitu dapat memperluas jangkauan pemasaran, mengurangi biaya promosi dan pembuatan laporan, dan mempermudah proses transaksi juala beli tanpa harus bertatap langsung [5]. Sedangkan menurut Adi Nugroho e-commerce memiliki beberapa kelebihan yaitu: dapat memeperluas mitra bisnis, memperpendek jarak, dan mengefisienkan waktu dalam berbelanja dan memberikan keamanan secara fisik terhadapa konsumen [6]. Para ahli menyatakan bahwa proses e-commerce dalam transaksi jual beli maupun kegiatan marketing lainnya lebih efisien kerena mengurangi biaya promosi dan memberikan kemudahan dalam memasarkan produk serta mempercepat proses transaksi [7]. Pernyataan tersebut serupa dengan penelitian yang dilakukan oleh [8] yang menjelaskan web e-commerce dapat memudahkan pembeli tanpa harus datang lansung ke tempat penjual, selain itu pembelian ataupun penjualan dapat diakses selama 24 jam selain itu $e$ commerce bisa dijadikan sebagai pasar virtual dimana informasi produk baru atau review dan konsultasi produk yang ada di pasar tersebut dapat dilihat, serta pemanfaatan teknologi ecommerce adalah strategi pemasaran produk yang dapat berdampak pada peningkatan pendapatan [9].

Industri kreatif yang ada di Polewali Mandar salah satunya adalah kain sutra mandar merupakan salah satu tenun tradisional Indonesia yang hingga saat ini tetap mempertahankan cara pembuatannya dengan menggunakan ATBM (Alat Tenun Bukan Mesin). Tenun Mandar dihasilkan sebagai khasanah budaya masyarakat Mandar yang mempunyai latar belakang historis dipakai dikalangan terbatas serta mencerminkan warisan kearifan lokal yang bersumber dari lingkungan alam sekitarnya. Kekhasan motif tenun mandar dengan karakter geometrisnya dan penggunaan material benang sutra emas dan perak khusus, serta pembuatannya yang masih tradisional dengan menggunakan Parewa Tandayang, memakan waktu 5 hingga 15 hari setiap lembarnya [10].

Kain Sutra Mandar memiliki hasil tenunan yang halus namun kaku. Material bahan tenun Mandar dihasilkan dari ulat sutra asli atau benang sutra yang dimport dari India atau China sebagai penghasil benang sutra berkualitas baik. Sepintas, tenun Mandar memiliki persamaan dengan kain tenun sutra daerah lain di Sulawesi, namun Lipa Sabbe Mandar memiliki ciri khusus yakni dari segi corak (sure' ataupun bunga) dan cara pembuatannya yang membuatnya terkenal ke daerah sekitarnya (bugis dan Makassar). Seiring kemajuan zaman, perkembangan pada masa ini, upaya-upaya kreatif telah dilakukan terhadap kain tradisional tenun sutra Mandar yaitu dengan cara disesuaikan dengan pola atau motif dan corak yang berkembang di masyarakat, diantaranya peristiwa-peristiwa penting di kalangan masyarakat yang muncul, nama tokoh, nama lagu dan lainnya. yang mengilhami corak kain tenunan khas Mandar seperti diantaranya nama Sureq Kepala Daerah, sureq Kucing garong dan lainnya. Kain 
Sutra yang dapat menjadi berbagai produk fashion dan aksesoris unik lainnya. Namun, saat ini para penenun masih memproduksi secara tradional dan mengalami kesulitan dalam memasarkan produk tersebut, karena pemasaran yang dilakukan sampai saat ini masih terbatas pada event atau pameran budaya yang diikuti oleh para UMKM yang dominan masih bersifat individual dengan jumlah produk yang terbatas, sehingga hanya kalangan masyarakat tertentu yang memperoleh informasi mengenai kain sutra tersebut [10].

Dengan menggunakan e-commerce memudahkan pelaku bisnis dalam memberikan informasi terkait dengan harga atau melakukan customisasi produk atau jasa yang ditawarkan secara cepat melalui website. Penggunaan e-commerce membuat konsumen dapat menghemat waktu, dan membandingkan harga lebih mudah dan fasilitas ini juga dikombinasikan dengan pembayaran yang cepat, pelacak order dan kecepatan pengiriman kepada konsumen [11].Penelitian lain yang dilakukan oleh [12] menjelaskan bahwa dengan merancang sebuah sistem yang berbasis web dapat menampilkan seluruh informasi barang, bahan, serta proses pemesanan barang. Dengan demikian penyampaian informasi tentang produk tersebut dapat tersebar secara luas dengan cepat melalui jaringan internet.

Berdasarkan permasalahan yang telah dijelaskan sebelumnya, adanya kendala dalam memasarkan sarung sutra mandar sehingga diperlukan suatu media yang dapat digunakan untuk memasarkan produk tersebut yang dapat menjangkau semua area tanpa dibatasi ruang dan waktu. Penelitian ini bertujuan untuk merancang dan mengimplementasikan e-commerce sebagai solusi dari kendala pemasaran sarung sutra mandar khususnya di Polewali Mandar.

\section{METODE PENELITIAN}

Jenis penelitian yang digunakan dalam penelitian ini adalah penelitian R \& D (Research and Development) untuk menghasilkan suatu produk dan menguji ke efektifannya. Model pengembangan yang digunakan mengadaptasi adalah pendekatan prototype. Mengemukakan bahwa dengan menggunakan pendekatan prototype, konsumen dan tim pengembang dapat mengklarifikasi kebutuhan dan interpretasi mereka [13].

\subsection{Jenis Data}

Jenis data yang digunakan dalam penelitian ini ada dua yaitu data primer dan data sekunder. Menurut Siregar data primer adalah data yang diolah dan dianilisis oleh peneliti dari data yang diambil dari objek penelitian, dan data sekunder adalah data yang diterbitkan atau digunakan oleh organisasi yang bukan pengolahnya [14]

\subsection{Teknik Pengumpulan Data}

Metode pengumpulan data yang digunakan pada penelitian adalah studi literatur, observasi, wawancara dan penyebaran angket. Studi literatur dilakukan untuk mendapatkan informasi dengan mencari data, buku-buku serta dokumen yang berhubungan dengan penelitian yang dilakukan. Observasi digunakan langsung oleh peneliti untuk melihat bagaimana respon pembeli terhadap pemasaran sarung sutra menggunakan sistem e-commerce yang akan dikembangkan. Wawancara dilakukan dengan para penenun dan pemilik toko sarung sutra mandar atau biasa disebut lipaq sa'be serta dinas terkait, dari hasil wawancara tersebut dapat disimpulkan bahwa di Kabupaten Polewali Mandar dalam pemasaran sarung sutra mandar selama ini belum adanya media yang mendukung seperti website dalam promosi selama ini dan masih menggunakan media konvensional sehingga masih kurang maksimal. Penyebaran angket digunakan untuk pembuatan aplikasi e-commerce. Angket yang telah disusun menggunakan skala Likert. Menurut [15] "Skala Likert digunakan untuk mengukur sikap, pendapat, dan persepsi seseorang atau sekelompok orang tentang fenomena sosial. Dalam penelitian, 
fenomena sosial ini telah ditetapkan secara spesifik oleh peneliti, yang selanjutnya disebut sebagai variabel penelitian. Dengan skala Likert, maka variabel yang akan diukur dijabarkan menjadi indikator variabel. Adapun indikator variabel yang digunakan dalam penelitian ini ada empat, yaitu: kualitas aplikasi, penggunaan aplikasi, kepuasan pengguna, dan dampak bagi UMKM. Indikator variabel ini digunakan untuk menilai sistem apakah sistem sudah berjalan dan mempermudah dalam pemasaran sarung sutra mandar.

\subsection{Tempat Penelitian}

Penelitian ini dilakukan di Kabupaten Polewali Mandar, subjek dalam penelitian ini adalah penenun dan UMKM kain sutra yang diambil dengan teknik pengambilan sampel purposif sampling. Teknik pengambilan sampel purposive sampling yaitu penarikan sampel dengan pertimbangan tertentu sesuai dengan tujuan penelitian [16].

\subsection{Teknik Analisis Data}

Teknik analisis data yang digunakan dalam penelitian ini adalah analisis deskriptif dengan pendekatan rumus persentase. Analisis deskriptif digunakan untuk menganalisis dan mendeskripsikan data dari penelitian yang telah dikumpulkan.

$$
P=\frac{F}{N} \times 100 \%
$$

dengan $\mathrm{P}$ adalah persentase yang diperoleh, $\mathrm{F}$ adalah frekuensi dari variabel yang diuji, dan $\mathrm{N}$ adalah jumlah responden [17].

\section{HASIL DAN PEMBAHASAN}

Interface media pemasaran kain sutra mandar di Polewali terbagi menjadi dua bagian utama, yaitu halaman login dan register, halaman e-commerce pemasaran sarung sutra mandar (front-end) dan dashboard untuk admin (back-end).

Tampilan awal dari halaman ini adalah halaman beranda yang menampilkan produk yang dipasarkan dan pelanggan dapat melakukan pencarian produk yang diinginkan dan memasukkannya kedalam keranjang belanja, melakukan proses transaksi pembayaran dengan menyetujui syarat dan ketentuan pembelian dari produsen, dan data transaksi tersebut akan tersimpan dalam sistem, setelah itu akan di verivikasi oleh sistem, setelah data valid sistem akan memberikan informasi pengiriman produk dan akan dikirim kepada pelanggan sesuai dengan syarat yang telah ditentukan. Sistem marketing pada aplikasi ini memiliki dua pengguna yang berperan sebagai admin dan pelanggan atau pengunjung web. Pengunjung web dapat melakukan registrasi untuk member, login member, dan akses menu fitur. Pengunjung web yang telah teregistrasi menjadi member dapat melakukan login dan menelusuri fitur, seperti memilih produ dan memasukkan ke dalam keranjang belanja, melakukan pembelian, pembayaran, dan contact dengan pemilik website. Sementara Pengunjung web yang belum melakukan registrasi hanya dapat melakukan akses menu yang ada tanpa bisa melakukan transaksi apapun. Untuk admin dapat melakukan akses menu, login admin, dan merubah data yang ada, mengecek tampilan website melalui akses menu fitur. Untuk menelusuri fitur lebih lanjut, seperti mengakses data member, produk, transaksi, dan pesan. admin harus melakukan login terlebih dahulu. Admin juga dapat melakukan merubah data mengenai penghapusan, penambahan, dan pengubahan informasi pada web tersebut. Aktivitas kegiatan yang ada dalam sistem yang dilakukan oleh admin dan pengunjung pada halaman web dapat dilihat pada gambar 1. Diagram Sistem Pemasaran e-commerce berikut ini: 


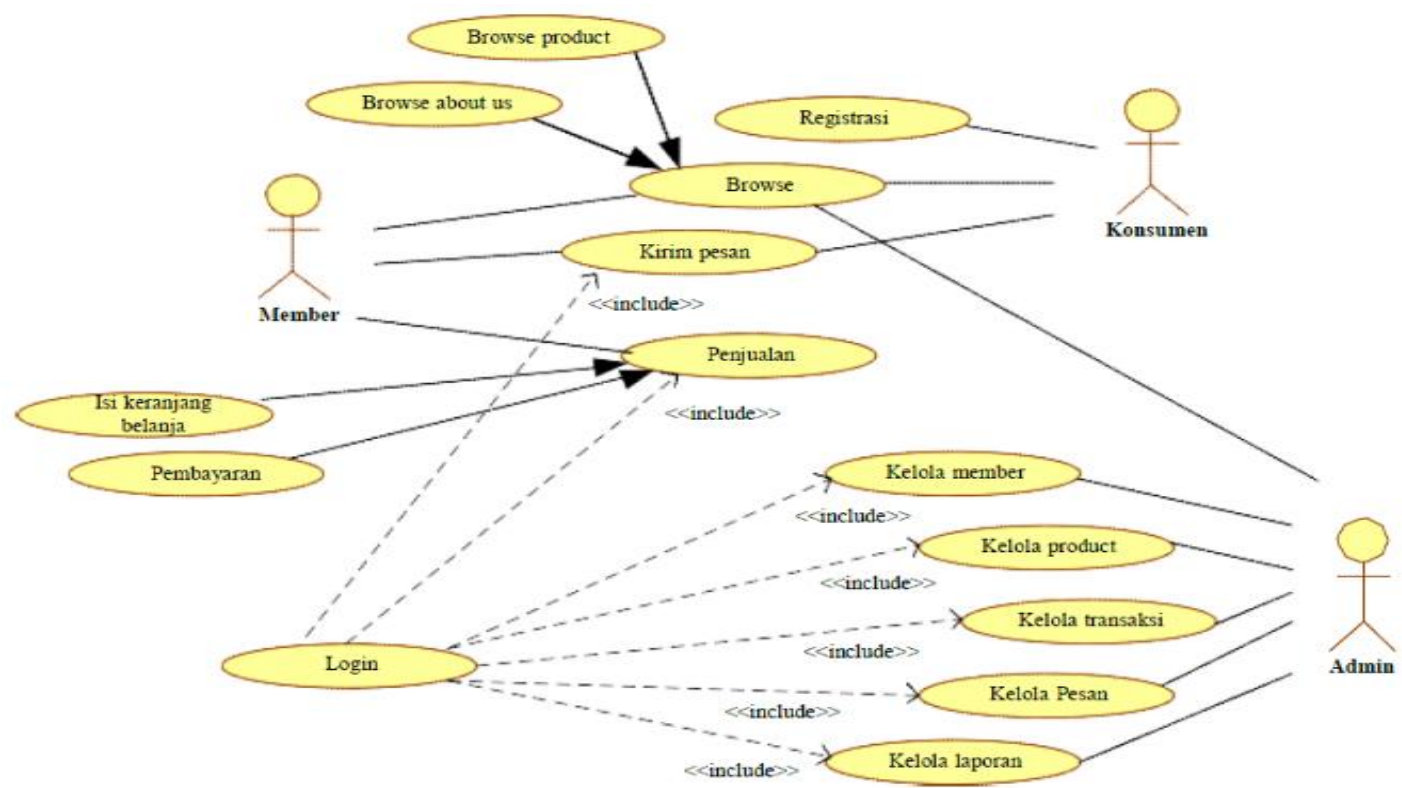

Gambar 1. Diagram Sistem Pemasaran e-Commerce

Bagian front-end berisi laman dari web e-commerce yang dapat diakses oleh konsumen atau pelanggan yang menampilkan informasi terkait produk sarung sutra mandar, yang terdiri dari menu home, profil, produk, cara pembelian dan pembayaran. Halaman utama ini bersifat umum jadi semua user bisa mengaksesnya langsung, tanpa harus melakukan login atau registrasi terlebih dahulu. Tampilan halaman utama seperti yang terlihat pada gambar berikut:

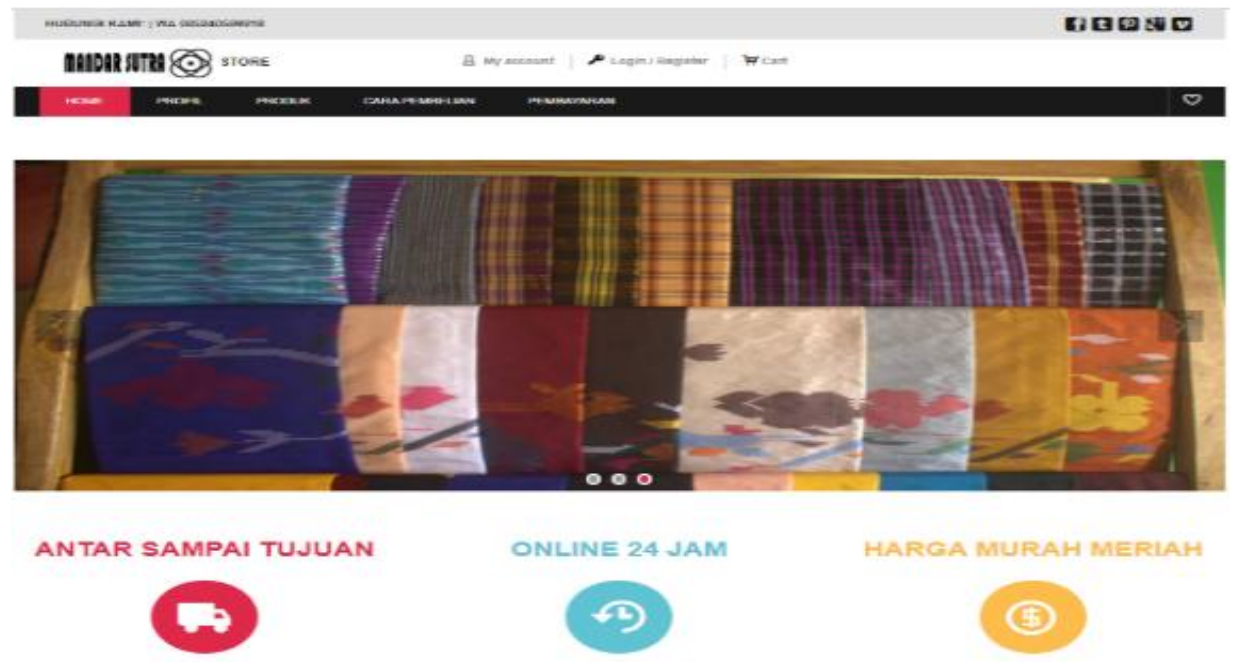

Gambar 2. Halaman Utama Web e-Commerce

Bagian back-end berisi laman yang hanya dapat diakses oleh admin untuk melakukan perubahan informasi dalam web e-commerce dengan memasukkan informasi mengenai produk yang akan dipasarkan melalui web. Memasukkan data semua barang dan informasi mengenai toko secara lengkap dan detail, maka semua informasi yang telah di entry oleh admin dapat dilihat oleh semua pengunjung yang mengunjungi web tersebut. Halaman detail product ini menampilkan informasi detil produk, admin dapat mengubah informasi data tersebut dengan 
memilih pilihan menu edit. Dengan memasukkan semua mengenai barang dan informasi mengenai toko maka produk akan terpampang dalam website beserta informasi produk secara detail sesuai dengan data yang telah dimasukkan. Tampilannya dapat dilihat pada gambar berikut:

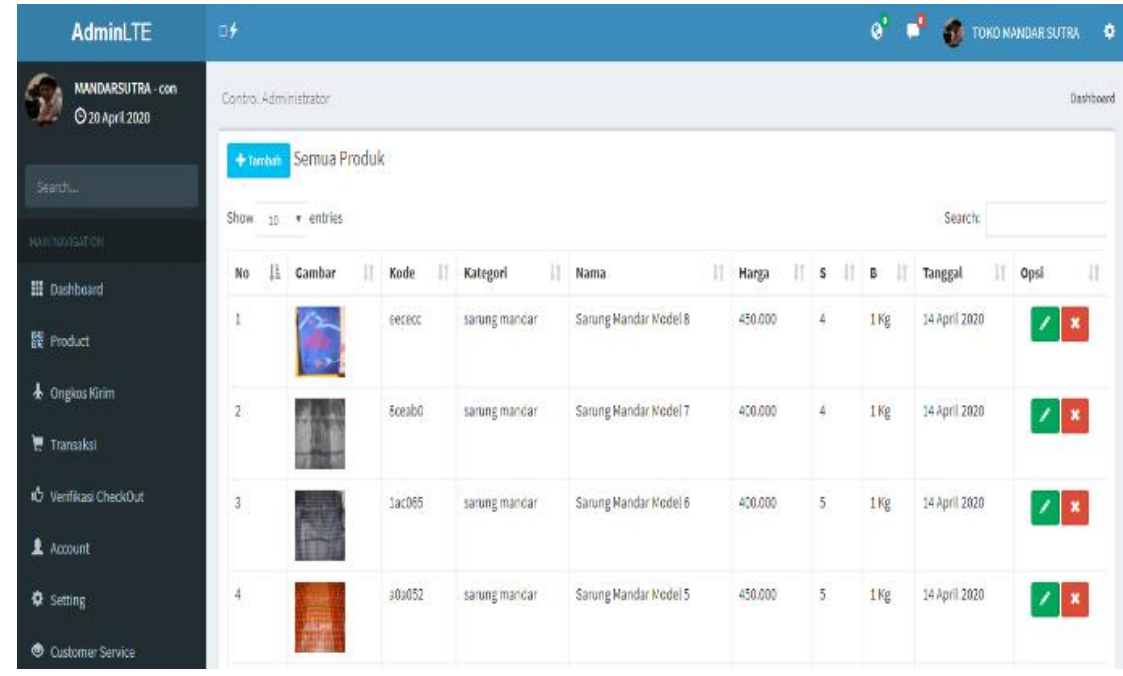

Gambar 3. Halaman Dasboard Admin Web e-Commerce

Uji coba yang dilakukan untuk menguji aplikasi e-commerce yang telah dibuat dengan jumlah responden 20 orang yang terdiri dari 18 orang konsumen dan 2 orang pihak UMKM. Tahap uji coba dilakukan untuk menghasilkan aplikasi yang bermanfaat. Dengan melihat 4 aspek dari aplikasi terbut yaitu: kualitas aplikasi, penggunaan aplikasi, kepuasan pengguna, dan dampak bagi UMKM atau toko.

Tabel 1. Hasil Analisis Uji Coba Aplikasi

\begin{tabular}{|l|c|c|c|}
\hline \multicolumn{1}{|c|}{ Indikator } & Rerata & Persentase & Kesimpulan \\
\hline Kualitas aplikasi & 3,39 & $84,65 \%$ & Sangat baik \\
\hline Penggunaan aplikasi & 3,26 & $81,58 \%$ & Sangat baik \\
\hline Kepuasan pengguna & 3,5 & $87,5 \%$ & Sangat baik \\
\hline Dampak bagi UMKM & 3,68 & $92,11 \%$ & Sangat baik \\
\hline \multicolumn{1}{|c|}{ Total } & 3,38 & $84,60 \%$ & Sangat baik \\
\hline
\end{tabular}

Tabel 1 untuk indikator kualitas aplikasi berada pada kategori sangat baik dengan nilai rata-rata 3,39 dengan presentase $84,87 \%$, ini menunjukkan bahwa kualitas aplikasi menurut responden yang diuji rata-rata berpendapat sangat baik. Indikator penggunaan aplikasi pada kategori sangat baik dengan retata 3,26 dan persentase $81,58 \%$, menunjukkan bahwa penggunaan aplikasi sangat baik menurut responden yang diuji coba lapangan rata-rata berpendapat sangat baik. Indikator kepuasan pengguna pada kategori sangat baik dengan rerata 3,5 dan presentase $87,5 \%$, bahwa kepuasan pengguna menurut responden yang diuji coba lapangan rata-rata berpendapat sangat baik. Indikator dampak bagi UMKM pada kategori sangat baik dengan rerata 3,68 dan presentase 92,11\%, dampak bagi UMKM menurut responden yang diuji coba lapangan rata-rata berpendapat sangat baik.

Berdasarkan seluruh indikator respon pengguna pada uji coba lapangan dengan jumlah sembilan belas orang terdiri dari tujuh belas orang konsumen sebagai client dan dua orang pihak 
UMKM sebagai server atau admin, menunjukkan rerata 3,38 dengan presentase $84,60 \%$ dengan kategori sangat baik, dapat disimpulkan bahwa pemanfaatan aplikasi e-commerce sangat membantu dalam pemasaran sarung sutra mandar, hal ini sesuai dengan penelitian yang dilakukan oleh Pamungkas bahwa e-commerce menjadi solusial alternatif kepada produsen agar penjualan semakin meningkat karena dapat diakses dimana saja dan kapan saja [18]

\section{KESIMPULAN}

Berdasarkan hasil dan pembahasan sebelumnya dapat disimpulkan bahwa hasil dari penelitian ini adalah menghasilkan sistem e-commerce yang dapat membantu pemasaran sarung sutra mandar. Dengan adanya sistem e-commerce, dapat memperluas jangkauan pemasaran dengan mempromosikan dan memasarkan sarung sutra mandar. Pelanggan dapat memperoleh informasi yang mengenai barang yang, dan melakukan transaksi pembelian atau pemesanan secara online kapan saja tanpa harus mencemaskan keterbatasan waktu dan tempat. Kemampuan aplikasi dengan digitalisasi penjualan memberikan banyak peluang baru. Meminimalisasi biaya promosi pada pemasaran untuk mencapai efisiensi dan efektivitas promosi dan pemasaran barang atau produk.

\section{SARAN}

Adapun saran untuk penelitian selanjutnya adalah perancangan sistem e-commerce ini dapat dikembangkan melalui aplikasi berbasis android yang dapat diakses menggunakan perangkat mobile phone.

\section{DAFTAR PUSTAKA}

[1] E. Agung Wibowo, 2014, "Pemanfaatan Teknologi E-Commerce Dalam Proses Bisnis," J. Equilibiria, Vol. 1, No. 1, [Online].

Available: https://www.journal.unrika.ac.id/index.php/equi/article/view/222.

[2] H. Maula, Shabur Miftah; Susilo, 2015, "Implementasi E-Commerce Sebagai Media Penjualan Online (Studi Kasus pada Toko Pastbrik Kota Malang)," J. Adm. Bisnis, Vol. 29, No. 1, [Online].

Available:

http://administrasibisnis.studentjournal.ub.ac.id/index.php/jab/article/view/1165/1452.

[3] H. ;Wahyu Purnamasari; Yunita, Pradhanawati; Ari, 2015, "Analisis Peluang ECommerce Dalam Pengembangan Usaha Mikro, Kecil, dan Menengah Produk Batik. (Studi Kasus pada Usaha Batik di Semarang)," J. Ilmu Adm. Bisnis, Vol. 4, No. 4, [Online]. Available: https://ejournal3.undip.ac.id/index.php/jiab/article/view/9226.

[4] F. Prasetiyo; Budi, 2020, "Analisa Faktor -faktor E-Commerce Dalam Membentuk Customer Satisfaction Millenial Bukalapak," Ris. J. Akunt., Vol. 4, No. 1, [Online]. Available: https://owner.polgan.ac.id/index.php/owner/article/view/177/111.

[5] D. Ahmadi, Candra; Hermawan, 2013. E-Business dan E-Commerce, I. Andi, Yogyakarta. 
[6] A. Nugroho, 2016. E- Commerce: Teori dan Implementas, Ekuilibria, Yogyakarta.

[7] Indonesia Student, 2017, "Pengertian E-Commerce Menurut Para Ahli Lengkap," https://www.indonesiastudents.com/pengertian-e-commerce-menurut-para-ahli/ (accessed Aug. 14, 2020).

[8] Adiwihardja; Cep, 2016, "Ecommerce Sebagai Model Inovasi Teknologi Strategi Enterpreneur Menurut Preferensi Pengguna pada Jakartanotebook.com," BINA Insa. ICT J., Vol. 3, No. 1, [Online]. Available: https://media.neliti.com/media/publications/234400-ecommerce-sebagai-model-inovasiteknolog-0a53e74f.pdf.

[9] T. W. Mumtahana; Hani Atun, Nita; Sekreningsih, 2017, "Pemanfaatan Web ECommerce Untuk Meningkatkan Strategi Pemasaran," Khazanah Inform., Vol. 3, No. 1.

[10] D. Bahrum, Syarifuddin; Anwar, 2009, Tenunan Tradisional Sutra Mandar di Sulawesi Barat. Jakarta: Direktorat Jendral Nilai Budaya, Seni dan Film, I. Direktorat Jendral Nilai Budaya, Seni, dan Film, Jakarta.

[11] Veza; Okta, 2019, "Perancangan E-commerce Untuk Memperluas Produk Komunikasi di PT. Golden Communication Berbasis Web Mobile,” J. Tek. Ibnu Sina, Vol. 4, No. 1.

[12] S. Kusuma Dewi And A. Kesy Garside, 2016, "Perancangan Website Sebagai Media Promosi dan Penjualan pada Home Industry Abon," J. Tek. Ind., Vol. 15, No. 2, p. 170, Mar. doi: 10.22219/JTIUMM.Vol15.No2.170-181.

[13] Sudaryono, 2015, Metodologi Riset di Bidang IT. Andi, Yogyakarta.

[14] S. Siregar, 2017, Statistik Parametrik untuk Penelitian Kuantitatif, 5th ed. PT Bumi Aksara, Jakarta.

[15] Sugiyono, 2015, Metode Penelitian Kuantitatif, Kualitatif, dan R\&D, Alfabeta, Bandung.

[16] S. Arikunto, 2013, Prosedur Penelitian Suatu Pendekatan Praktik, 15th ed. Rineke Cipta, Jakarta.

[17] N. Sujadna, 2011, Penilaian Hasil Proses Belajar Mengajar. PT Remaja Rosdakarya, Bandung.

[18] S. Pamungkas Noor; Gusti Adia, 2020, "Implementasi E-Commerce Menggunakan Content Management System untuk Pemasaran Produk pada Lumi Distro Dengan Pendekatan Business Model Canvas," J. Idealis, Vol. 3, No. 1. 